\title{
Elements of syntax in the systems of three language-trained animals
}

\author{
EDWARD KAKO \\ University of Pennsylvania, Philadelphia, Pennsylvania
}

\begin{abstract}
Which properties of syntax are uniquely human, and which can be acquired by other animals? Relevant evidence is provided by work with three language-trained animals: the African gray parrot Alex, who can produce and comprehend a small fragment of English; the bottle-nosed dolphins Ake and Phoenix, who can comprehend a gestural and an acoustic language, respectively; and the bonobo Kanzi, who can produce combinations of lexigrams and comprehend a significant fragment of English. The systems of these animals are examined for evidence of four core properties of syntax: discrete combinatorics, category-based rules, argument structure, and closed-class items. Additional studies that explore further what these animals can learn about these core properties are suggested.
\end{abstract}

Of the many capacities that appear to separate us from other animals, language is regularly identified as the single most crucial one, and questions about human uniqueness and human evolution have often focused on the species-specificity of language. Not all the components of language have received equal attention, however. Despite the fact that language is organized at multiple levels, from sounds (at the lowest level) to conversations (at the highest), linguists and psycholinguists have paid the most attention to syntax, and with good reason: By organizing words and their inflections into patterns reflecting the thoughts of the speaker-patterns that listeners can readily decode - syntax makes possible the efficient mind-to-mind contact that gives language its power.

To determine the species specificity of syntax, we must have both a definition of syntax and informative data from other species. Recent advances in linguistic theory and in comparative cognition have provided what we need, so that we can now approach this issue in a way previously not possible. ${ }^{1}$ In what follows, I first define human syntax in terms of four core properties. Following that, I provide essential background on the three species whose language-trained capacities constitute our data base: the African gray parrot, Psittacus erithacus (Pepperberg, 1983, 1990a, 1992), the bottle-nosed dolphin, Tursiops truncatus (Herman, 1987; Herman, Richards, \& Wolz, 1984), and the pygmy chimpanzee, or bonobo, Pan paniscus (Greenfield \& Savage-Rumbaugh, 1990; Savage-Rumbaugh

A portion of this paper was presented at the Second International Conference on the Evolution of Language, London, April 1998. I thank Robert Seyfarth and Dorothy Cheney for reading several drafts of this paper and for talking often and enthusiastically about these issues. Thanks also to Toby Mintz, Letty Naigles, Bill Timberlake, Laura Wagner, and three anonymous reviewers for their many helpful suggestions at different stages of writing. Correspondence should be addressed to E. Kako, Department of Psychology, University of Pennsylvania, Philadelphia, PA 19104-6196 (e-mail: kako(a)psych.upenn.edu). et al., 1993). ${ }^{2}$ Finally, I look for evidence of the four core properties in the systems of these animals.

\section{THE CORE PROPERTIES OF SYNTAX}

Broadly speaking, the concept of syntax appears in three forms. In its first, most generic form, syntax is defined as a set of rules for assembling units of any type into larger units. On this definition, many kinds of behavior can be called syntactic, including human music (Jackendoff, 1983), the songs of birds (Marler, 1984), and the grooming patterns of rats (Berridge, Fentress, \& Parr, 1987). Although useful in many contexts, this definition casts too wide a net for our purposes, and so we will not consider it further. In its second, far more restrictive form, syntax cashes out as all the properties manifest in human language. An animal would have syntax only if its communication system showed long-distance dependencies (e.g., the agreement of subject and verb despite intervening words in The HOTEL that I stayed in WAS very comfortable), binding (e.g., the restriction of the reference of him in John shaved him to someone other than John), movement (e.g., the displacement of eat's direct object to sentence-initial position in the question What did Henry eat?), and so on (cf. Haegeman, 1991). We can say with near certainty that no animal can acquire a system with all of these features. Nonetheless, a nonhuman animal might be able to acquire a subset of these features. This leads us to syntax in its third form: a set of structural properties that define the core of syntax. The question now becomes: Which features form the core?

Over the years, a number of researchers have attempted to identify these properties. In their design features approach to language, Hockett and Altmann (1968), for instance, suggested two features of language that are especially relevant to syntax: discreteness- "The possible messages in any language constitute a discrete repertoire" - and openness-"New linguistic messages are coined freely and easily, and, in context, usually understood" 
(p. 63). The property of discreteness is echoed in McNeill's (1970) notion of a combining system, wherein "each new combination stand[s] for a new message" (p. 38). Both openness and discreteness appear in Demers's (1988) definition of the structural properties of syntax: "Human language is made up of several levels of discrete units, at each level of which units are combined according to abstract rules of organization" (p. 322). Greenfield and Savage-Rumbaugh (1990), in their definition of a syntactic rule, have argued that "Each component of a combination must have independent symbolic status"; that "[a] rule must specify relations between categories of symbols across combinations, not merely a relation between individual symbols"; and that "[t]he rule must be productive" (p. 541).

Although these proposals all vary in detail, they converge on two syntactic properties: discrete combinatorics and category-based rules. I discuss both properties at some length below, along with two additional properties suggested by work in modern linguistic theory: argument structure and closed-class items.

\section{Discrete Combinatorics}

Language, to use the words of Pinker (1994), is a "discrete combinatorial system" (p. 84). When words combine, their meanings do not blend one into another, as do colors when they are mixed. Rather, their meanings also combine, in lawful ways prescribed by syntax. $A$ brown cow does not identify a concept intermediate between brown and cow (whatever that might be); nor does the sentence Peter likes pickles describe some bizarre hybrid of Peter, liking, and pickles. Word meanings by and large retain their semantic integrity. (I say "by and large" because the color of a brown cow is not the same as the color of a brown haze; words can sometimes tweak the meanings of other words in their presence, but only slightlycf. Partee, 1995). What changes is how the words relate to one another, and herein lies the vast power of syntax to generate new messages.

Were language not a discrete combinatorial system, our expressive capacities would be severely limited. New messages could come only in the form of new intermediate states. Very few things in the world can adequately be described in this graded fashion-perhaps only emotions, motivational states, and some properties. Novel configurations of objects, events, locations, and so on would literally be unspeakable. Given that the world frequently surprises its inhabitants, the combinatorial properties of syntax are tremendously useful.

\section{Category-Based Rules}

Speakers of a language know how the elements of their language are put together. They know which sequences are good and which are bad. In English, we recognize that The woman clawed the cat is a good sentence (albeit one that describes a surprising event). But we re- ject The clawed woman cat the as being unacceptable. How can we characterize our knowledge of these sequences? One possibility is that we have learned the order in which particular words appear: We've learned that the can be followed by woman, which can be followed by clawed, which can be followed by the, which in turn can be followed by cat. The sequence The clawed woman cat the offends us because clawed has never been followed by woman. This word chain model of grammar (to use Pinker's, 1994, phrase) has an appealing simplicity. But it fails to explain a fundamental property of human language: the ability to say completely new things. A word chain model knows only what it has heard; history repeats itself with minimal innovation. People, on the other hand, can produce sentences that no one has ever uttered before, sentences like Colorless green ideas sleep furiously (Chomsky, 1965), which is a perfectly lawful (if meaningless) sentence of English. Surely there is no link from green to colorless or from furiously to sleep. What have we learned about language that allows us to produce such novel sequences?

What we have learned is not the order of particular words - cat, claw, woman, the - but the order of classes of words-noun, verb, determiner, and so on. Moreover, we have learned how these word classes collectively form phrases. A noun phrase, for instance, contains a noun (e.g., books), which can be preceded by a determiner (THE book) and/or one or more adjectives (a LONG BORING book) and can be followed by one or more prepositional phrases (books FROM THE LIBRARY) or by an embedded clause ( $a$ book THAT I HAVE NOT READ). Because the rules of phrase structure are built around categories of words, I can say things that no one has ever said before. I can say, for instance, that I had a dream in which a tree scolded me, even though the probability of scold following tree is vanishingly small. Or I can say that I recently bought a brand new computer program called Gorp, and that Gorp crashed my $P C$. The fact that Gorp was not a word until recently doesn't prevent me from building a sentence with it; all I need to know is that it's a noun, and many other things follow automatically - for instance, that it can precede a verb. The capacity to say new things brings with it clear advantages, again because the world can be a surprising place, full of novel entities, properties, and events worth talking about.

\section{Argument Structure}

Human languages relate events and their participants in a highly systematic fashion, through a system called argument structure. Argument structure is built around the primary site of predication in language - the verb, without which no sentence is complete. To possess argument structure, a linguistic animal must know (1) how many participants are involved in the event that a verb labels and, therefore, how many arguments (in the logical sense) are associated with the verb and (2) how those arguments should be assigned to syntactic positions in the 
sentence. Let's consider each component of argument structure in turn.

Consider the verb give. An event of giving by necessity has three participants: a giver, a thing given, and a recipient. Any sentence with the verb give must express all three. Hence John gave the book to Mary is perfectly acceptable, but John gave, John gave the book, and John gave to Mary are not, because they all lack the required number of role players. All verbs are, like give, picky about the company they keep, in ways that depend crucially on the nature of the events they label. Consider cry: Because crying is ultimately the act of individuals, Seymour cried is fine, but Seymour cried a terrible tale is not. And the verb kiss, more outgoing than cry but less gregarious than give, tells a story with two participants: the kisser and the kissee. Hence Susan kissed Bob is entirely acceptable, whereas Susan kissed and Susan kissed Bob her lipstick are not. In logical terms, we can talk about each verb as having a certain number of places for its arguments: give is three-place, kiss two-place, and cry oneplace. In this way, each verb's meaning dictates the shape of every sentence it inhabits.

Argument structure specifies not only that all arguments associated with a verb be mentioned in the sentence but also that those arguments be linked to particular syntactic positions - subject, direct object, indirect object, and so on. ${ }^{3}$ The linking of an argument to a syntactic position depends on its thematic role-the role it plays in the event. In simple, active sentences of English, the doer of an action, or the agent, appears as the subject; the done-to, or the patient, usually (although not always) appears as the direct object; and the recipient usually (although, again, not always) appears as the indirect object (Madeline gave some cookies TO MITCHELL). Other thematic roles, such as locations and paths (at the store, to the moon), typically appear as prepositional phrases following the verb. Note that these linking rules (as they are called) run in one direction only. Although all agents are subjects, not al! subjects are agents (just as not all direct objects are patients); the thematic role assigned to a syntactic position depends on the verb. A subject can also be, among other things, an experiencer (Bob fears spiders) and a theme (Smoke filled the room), depending on the thematic profile of its verb.

Over the last 15 years, argument structure has assumed a central place in linguistic theory, prompting much fruitful work (e.g., Baker, 1992; Dowty, 1991; Goldberg, 1995; Grimshaw, 1990; Jackendoff, 1987; Levin, 1993; Pinker, 1989; Stowell, 1992; van Hout, 1996). Although the account I've given above is highly simplified, ${ }^{4}$ the essential point should be clear: Events and their participants are related in a highly structured fashion, and the system for relating them forms a fundamental part of human language. Indeed, without argument structure, it would be difficult (if not, at times, impossible) to deduce from a sentence who did what to whom. Consider the interpretive troubles posed by the sentence $A$ lion killed, which omits one of the arguments of kill. Did a lion kill someone? Or did someone kill a lion? The situation markedly improves for the sentence Fred killed a lion, but only if we can be sure who is the agent and who is the patient. Fred's skills as a hunter might help us decide between the two possible interpretations - but only if our expectations coincide with what has actually happened. With the linking rules provided by argument structure, the syntactic positions of Fred and lion tell us with certainty that Fred caused the lion's death. Argument structure ensures that listeners can accurately decode the thoughts of speakers, by demanding (1) that all participants in an event be mentioned in the syntax, ${ }^{5}$ and (2) that participants be assigned to different syntactic positions in accord with the roles they play in the event. As we inspect the data from Alex, the dolphins, and Kanzi, we will look separately for evidence of these two components of argument structure.

\section{Closed-Class Items}

All human languages possess two types of lexical items: items that primarily carry meaning and items that primarily provide structure. The first type includes nouns, verbs, and adjectives; it is called open-class because it readily admits new members (e.g., modem, fedex, ecological). The second type includes prepositions (e.g., in, through, above), determiners ( $a$ and the), quantifiers (e.g., some, many), and morphological markers (e.g., the past tense ending $-e d$, and the plural ending $-s$ ); it is called closed-class because it strongly resists the introduction of new members. These two classes have independent psychological status: Open-class items are typically acquired by children before closed-class ones (Gleitman, Gleitman, Landau, \& Wanner, 1988); focal brain injury can selectively disrupt one class while leaving the other largely intact (Caplan, 1992); and the two classes elicit distinct event-related brain potentials during on-line processing (Van Petten \& Kutas, 1991). Together, closedclass and open-class items cooperate in syntax to communicate meaning in a highly structured fashion. As I sketch precisely how this cooperation works, I will draw heavily on the work of the linguist Leonard Talmy (in particular, Talmy, 1988), who has written extensively about the complex interaction of these two systems. (For similar views, see Morrow, 1986.)

First and foremost, the two systems differ markedly in their content: Whereas open-class items can encode a virtually limitless set of rich concepts, closed-class items specify what Talmy calls a "crucial set of concepts, highly restricted" (p. 165). To take a simple example, English has many thousands of words for objects, some of them encoding very fine differences in structure. The distinction between cup and mug, for instance, is tiny. Both are typically used for the local transport and ingestion of liquids. Both are roughly the same shape (cylindrical). Both are enclosed only at one end. Perhaps the only difference between them is that a mug has a handle that enables the drinker to manipulate it when its contents are hot. De- 
spite their substantial structural similarities, however, we have two distinct words for these objects.

Whereas the noun system readily captures small differences like these, the preposition system is insensitive even to large differences. Streets, boxes, and catcher's mitts have little in common structurally (certainly less than cups and mugs). And yet we can say The ball is IN the street/ box/mitt. Here, in appears to be indifferent to the striking differences in the structure of the objects that follow it. All that seems to matter in deciding whether Object $\mathrm{X}$ can be in Object $\mathrm{Y}$ is that the latter have what could be construed as an interior space (although there is much debate about the meaning of even this little word; $c f$. Vandeloise, 1994).

Like the preposition in, closed-class items as a group have highly abstract meanings. Consider two other examples: the markers for number and time. In English, we have a single marker of numerosity, the suffix $-s$, which distinguishes only between one and more than one. Consequently there is no way to mark the difference between 2 ducks and 2,000 ducks, except by adding the appropriate open-class items, two and two thousand. In a similar vein, the morpheme, -ed marks an event as having happened in the past but does not indicate exactly when. Both Brutus killed Julius Caesar and Lee Harvey Oswald killed John F. Kennedy leave unspecified precisely how long ago these events took place. But we can recruit openclass items to modify these two sentences with the expressions two thousand forty-two years ago and thirty-five years ago, respectively, to achieve much greater detail.

Having distinguished the two classes of words, we can now see how they interact. Consider the examples below from Talmy (1988), where the closed-class items are in italics and the open-class ones in normal type.

\section{$A$ rustler lassoed the steers.}

Note what this sentence is telling us: A person whose vocation is the illegal acquisition of cattle (although not a person we know or have been talking about; otherwise we would see THE rustler) at some point in the past deployed a large, looped rope to capture a group of steers that we know or have been discussing (although we don't know exactly how many, just more than one). Now let's alter the closed-class items in Example 1 and inspect the result.

Will the rustlers lasso $a$ steer?

Here, the content of the sentence has remained largely the same. We're still talking about cattle, a lasso, and the illegal acquisition of the former by means of the latter. But the configuration of the content is decidedly different: The sentence is a question rather than a statement, the time frame is the future, there is now a group of rustlers that we presumably know something about, and only one steer is in jeopardy. These differences result directly from the operation of the closed-class items on the openclass ones.

Now, let's leave the closed-class items in Example 1 fixed and, instead, change the open-class ones.
$A$ machine stamped the envelopes.

We have been catapulted into an entirely different scene, possibly a post office, in which the stamping of envelopes took place some unspecified time ago. The change here from Example 1 to Example 3 is far more dramatic than the change from Example 1 to Example 2. This difference suggests that open-class and closed-class words play different roles on the linguistic stage. To invoke a theatrical metaphor, open-class items are like the playwrights of language, whose choice of words determines what the play is about to begin with. Closed-class items, by contrast, are more like the costume and set designers of a play, with the power to alter the period and "feel" of a dramatic piece (and thereby lend it new narrative implications), but with no power to alter its original content.

Why do we need decorators and costumers in the first place? What do closed-class items contribute to language? In response to the first question - and, by implication, to the second-Talmy (1988) writes that closed-class items

act as a scaffolding or framework across which contentful material can, in effect, be splayed or draped. It can be posited that such structuring is necessary for a disparate quantity of contentful material to be able to cohere in any sensible way and hence to be amenable to simultaneous cognizing as a Gestalt. That is, without such structuring, not only does the inventory of concepts available for expression in language become less coherent, but also any selection of such concepts concurrently juxtaposed by a sentence would tend to be only a collection of elements, rather than elements assembled so as to convey an integrated idea or thought complex. (p. 196)

In other words, closed-class elements take what would otherwise be an ambiguous string of words--for instance, Rustler lasso steer - and turn it into something coherent, meaningful, and considerably more informative. Although linguistic communication could certainly take place without closed-class items, its complexity would be severely limited.

Consider the case of pidgin languages (established by adults brought into contact for some common purpose, such as commerce), which typically have few closed-class items: Although pidgin speakers do communicate; their sentences are often far more chaotic and more ambiguous than those in full language; when closed-class items are added to pidgins by subsequent generations of child learners (in the process of creolization), the system becomes much more structured, and ambiguities are significantly reduced (Bickerton, 1990).

A definition of syntax in hand, we now turn to some background on the three animals which will form our data base.

\section{THREE LANGUAGE-TRAINED ANIMALS}

\section{The African Gray Parrot}

In June 1977, Irene Pepperberg purchased a 13month-old male African gray parrot (Psittacus eritha$c u s)$ at a Chicago pet store and began an ambitious pro- 
ject in interspecies communication. Using a method built around intensive social interaction with human trainers, Pepperberg has taught her parrot, named Alex, to produce and comprehend dozens of English words. (The description of method that follows is drawn from Pepperberg's first formal report on Alex, Pepperberg, 1981.) This method, called the model-rival (or $M / R$ ) technique, requires Alex to compete with human rivals for his trainer's attention. Trainer A asks Trainer B to produce the label of an object (e.g., pasta); when B does so, $A$ then asks Alex to do the same. Periodically, A and $B$ reverse roles, and Alex is regularly encouraged to participate. Alex's rewards are intrinsic: Rather than getting food when he succeeds, he gets the object he is being asked to label. If he prefers a different object, he must first produce the label for the test item. As one might expect, Alex rarely produces new words accurately. His trainers shape his articulation over time by successive approximation: Every time they present the object anew, they require him to approximate more closely the English target. The trainer helps with cues such as, "Look at the PAPER! See the PAPER!" with the target in the stressed, sentence-final position. Alex is not tested on his understanding of a new word until he can produce it well enough to be understood by blind coders (thereby eliminating possible confusion over what he actually said). Alex is thought to have learned a word when he can produce it correctly $80 \%$ of the time or better when asked to label an object or one of its properties (e.g., "What's this?" or "What color?").

As of 1990, Alex had a vocabulary of about 80 items, including object words (e.g., rock, tray, paper), color words (e.g., green, blue, gray), shape phrases (e.g., threecorner [triangle], four-corner [square]), action phrases (e.g., wanna go $X$ [where $\mathrm{X}=$ a location] and come here), numbers (two, three, four, five, and sih [six]), and the functional use of the words nuh (no) and yeah (yes). Impressively, Alex has learned to produce and comprehend sequences of these words. Asked "What's this?" of a piece of orange rawhide, he responds, "Orange hide." And when he wishes to know what something is called, he will ask, "What's this?" (for an object label) or "What color?" (for a property label).

Pepperberg's primary purpose in teaching Alex to produce and comprehend a tiny fragment of English has not been to assess his language-learning abilities. Rather, she has used these skills to assess Alex's cognitive capacities, which are striking: He can classify according to color and substance (Pepperberg, 1983), count up to six, (Pepperberg, 1987b), and understand the concepts of same and different (Pepperberg, 1987a), as well as the concept of absence (Pepperberg, 1988). Although Alex is not studied for his linguistic capacities as such, his remarkable achievements suggest that his will be an informative case.

\section{The Bottle-Nosed Dolphins}

In the early 1980's, Louis Herman and his colleagues set out to teach an artificial language to two young fe- male bottle-nose dolphins (Tursiops truncatus), Akekamai (Ake) and Phoenix. Ake was taught a gesture-based language, with signs given by the trainer standing in her tank; Phoenix was taught an acoustic language, with synthesized click-like words transmitted from an underwater speaker. Each language contained a vocabulary of from 35 to 40 items (with substantial, although not complete, overlap between the two), which referred to objects in the tank (e.g., CHANNEL, GATE, PERSON, SPEAKER, BALL, HOOP), actions that could be executed relative to those objects (e.g., TOSS, [go] OVER, [go] UNDER, FETCH, [put] IN), and modifiers of object location (SURFACE, BOTTOM) or direction (RIGHT, LEFT). In addition, the dolphin language contained what Herman (1987) calls "control and function words": YES, NO, ERASE (a command to ignore the previous words in a sentence), and QUESTION (a signal to report on the presence or absence of an object in the tank). If a dolphin completed a command successfully, she heard a three-word acoustic string, YES [her name] FISH, which was followed by a reward of food. If she was unsuccessful, she heard only her name, calling her back to the trainer's station.

The dolphins were taught to respond to two types of sentences: nonrelational and relational. Nonrelational sentences required them to manipulate or interact with only one object. The syntax for this type of command, identical in both languages, was (MODIFIER) OBJECT ACTION (where the parentheses indicate that the MODIFIER was optional). If Ake was given the command PIPE TAILTOUCH, she was allowed to touch any of the pipes in her tank with her tail flukes. If given the command RICHT PIPE TAIL-TOUCH, she was required to touch only the pipe located on the right. (Whenever a sentence contained a modifier, the dolphins always had two or more choices available.)

Relational sentences required the dolphins to transport one item to another. For Phoenix, the syntax of these commands was OBJECT $1+$ RELATION + OBJECT $_{2}$, whereas for Ake it was $\mathrm{OBJECT}_{1}+\mathrm{OBJECT}_{2}+$ RELATION. These commands required the dolphins to understand links between syntactic position and thematic role: For Phoenix, OB$\mathrm{JECT}_{1}$ was the transport object and OBJECT ${ }_{2}$ the destination object, whereas for Ake, OBJECT, was the destination object and $\mathrm{OBJECT}_{2}$ the transport object. Thus, if Ake was given the instruction WATER RIGHT BASKET FETCH, she had to transport the basket floating to the right in her tank over to one of the nearby water pipes. If, however, she was given the instruction RIGHT WATER BASKET FETCH, she was supposed to transport the basket of her choice over to the water pipe on the right of her tank. The dolphins could correctly enact relational sentences only by inferring the thematic roles of objects (transport vs. destination) from their syntactic positions.

\section{The Bonobo}

Some of the strongest claims about the syntactic capacities of nonhuman animals have come from Sue SavageRumbaugh's work with the bonobo (Pan paniscus) Kanzi. 
When young, Kanzi was exposed, without explicit training, to the artificial lexigram system named Yerkish (after the Yerkes Primate Center), which was being taught to his adoptive mother, Matata. When Matata was removed temporarily for breeding, Savage-Rumbaugh discovered that Kanzi had learned the meanings of many Yerkish symbols simply by observing the interactions between his mother and her trainers. Savage-Rumbaugh and her colleagues thereafter focused their efforts on teaching Yerkish to Kanzi. Unlike the common chimpanzees previously studied by Savage-Rumbaugh (e.g., SavageRumbaugh, Rumbaugh, \& Boysen, 1978; SavageRumbaugh, Rumbaugh, Smith, \& Lawson, 1980), Kanzi did not require intensive training and reinforcement. Rather, he acquired his knowledge of Yerkish through ordinary, unreinforced "dialogue" with his trainers, who would activate the appropriate lexigram on Kanzi's computerized keyboard whenever they uttered a word that had a lexigrammatic counterpart. All lexigrammatic activity, both from Kanzi and from his trainers, was tabulated by computer. This automated record-keeping has made available a rich corpus of data unlike any other in previous ape language projects. Together with the records of context kept by his trainers, they permit a systematic evaluation of Kanzi's linguistic abilities.

Greenfield and Savage-Rumbaugh (Greenfield \& Savage-Rumbaugh, 1990; hereafter, G\&SR) have amassed a corpus of more than 13,000 utterances, most of them just single lexigrams, collected over a 4-month period in 1986. Of these, about 1,400 were combinations of two or more elements. G\&SR eliminated all those utterances that were solicited or imitated (although they do not specify the criteria for identifying utterances of this type), along with any that did not have accompanying context provided by at least two researchers. A total of 723 twoelement combinations remained, including combinations of lexigram with lexigram (e.g., MATATA BITE, a command directed toward Kanzi's mother) and (in the great majority of cases) lexigram with gesture (e.g., CARRY + [gesture to person], a command directed toward one of his caretakers). Kanzi's gestures labeled objects or people, singled out specific entities in a demonstrative fashion, or labeled (differentially) the actions come and go.

Simultaneous with using the lexigram system, Kanzi's caretakers also spoke English to him. Eventually, it became apparent that he understood their utterances, which often contained information too complex to be communicated in Yerkish. Savage-Rumbaugh and her colleagues (Savage-Rumbaugh et al., 1993) then set out to study Kanzi's knowledge of English - a language he could not produce--by comparing his sentence comprehension abilities (at age eight) to those of a human child named Alia (at age two).

Kanzi and Alia were tested separately, Kanzi by Sue Savage-Rumbaugh and Alia by her mother, Jeannine Murphy, a research associate. Over numerous testing sessions, each was presented with several hundred sentences ( 653 for Kanzi, 587 for Alia), with substantial overlap in the two sets. Nearly all of the sentences were commands to perform an action either to or with one or more objects or people. Initially, the trials were administered with the experimenter in the same room with the subject; after a period of acclimation (at trial 244 for Kanzi and trial 180 for Alia), blind trials were carried out in which the subject could not see the experimenter. In cases of nonresponse, the experimenters intervened with prompts and repeats. If the subject failed completely to comply, the experimenter helped him or her to carry out the instruction properly. Scoring was stringent. Cases in which the experimenter had to demonstrate the correct action were always excluded, as were partially correct responses. Cases in which the experimenter intervened to redirect the subject's attention were not excluded, although these made up a relatively small proportion of correct trials $(20 \%$ for Kanzi and $17 \%$ for Alia). The subjects had ready access to multiple objects and people (who wore earphones to prevent them from giving inadvertent cues) and so could perform a wide range of actions in response to each command.

Test sentences were in general designed so that the meanings of the words alone would be insufficient for successful interpretation. Some sentences described actions that could not be deduced from prior knowledge of the objects involved (e.g., Put the money in the mushrooms), whereas others involved objects whose roles could easily be reversed (e.g., Put some milk in the water). The subjects therefore had to rely on structure to determine what was being asked of them. Sentences were presented naturally, with minor variations designed to keep attention (e.g., Take the telephone outdoors, Could you take the pine needles outdoors? and Can you take your collar outdoors?).

Both Kanzi and Alia proved adept at carrying out the commands issued to them. Kanzi was correct on $74 \%$ of all blind trials, Alia on $65 \%$. Excluding trials that required experimenter intervention, Kanzi was correct $59 \%$ of the time, Alia $54 \%$. Because I wish to focus on Kanzi's performance, I will say no more about Alia (see Savage-Rumbaugh et al., 1993, for more details). Suffice it to say that, in most instances, his performance did not differ significantly from hers.

\section{ELEMENTS OF SYNTAX IN THE SYSTEMS OF THESE ANIMALS}

\section{Discrete Combinatorics?}

Do these animals show evidence of discrete combinatorics? The answer is yes for all three species. For Alex, the expression rose paper refers to paper with the property of being colored rose, not to something intermediate between rose and paper. Similarly, Ake and Phoenix interpret PIPE TAIL-TOUCH as a command to perform an action on an object, the two words retaining their individual meanings. The items in Kanzi's Yerkish combinations (both lexigram with lexigram and lexigram with gesture) likewise preserve their identities, such that HUG + [gesture to person] expresses his wish that a caretaker 
hug him. And in English as well, Kanzi appears to recognize that the meanings of sentences are built up by combining the meanings of words, not by blending them, as is attested by his ability to enact English commands in the way that his human caretakers intend them.

It should not be surprising that these animals all possess discrete combinatorics, as this property of syntax is a prerequisite for all others. Indeed, a system could not have category-based rules, argument structure, or a distinction between closed- and open-class words unless words retained their meanings when combined. If these animals lacked discrete combinatorics, they would surely lack these other properties of syntax, and we would have little to discuss.

\section{Category-Based Rules?}

Alex. What does Alex know about the structure of the language he has been taught? Is his knowledge chainlike or category-based? Two phenomena suggest that his knowledge is category-based, at least in part: his correct identification of novel objects and his novel combinations of words with request markers.

When presented for the first time with rose paper, Alex called it "rose hide." After being allowed to chew on it, he called it "paper." When prompted with "What color?" he replied "rose"; prompted further with "Rose what?" he replied "rose ... paper" (with a brief pause between words). He subsequently identified "green cork," "blue peg wood," and "blue hide" on the first trial, although his trainers had never produced these combinations. (This and the following examples in this paragraph are from Pepperberg, 1981.) When presented with a (novel) piece of triangular rawhide, Alex first called it "three-corner paper." After being allowed to chew on it, he called it "three-corner hide" on four of five subsequent trials. Similarly, he called a piece of squarish rawhide "four-corner paper" until he was able to chew it, after which he called it "four-corner hide." And finally, after acquiring the word rock as the label for the property hard, Alex spontaneously produced the phrase "rock corn" one afternoon and was given a kernel of dried corn. Subsequently, he continued to ask for dried corn with that phrase.

When Pepperberg first acquired Alex, he was willing to undergo testing in only two places: his cage and his gym (a play area with numerous perches). His trainers therefore used expressions like "Wanna go gym" (and other variations) to coax him into going to that location. In late 1980 , in the midst of some chatter, Alex produced the expression, "Wanna go gym!" At first, Alex produced this expression when already in that location; his trainers would respond by saying things like, "You're already on the gym." Eventually, he produced the expression primarily when not on the gym; if he was there but wanted to move, he would say, "Wanna go gym - no" or "Wanna go ... wanna go ..." If his trainers said, "Wanna go back?" he would reply, "Yeah." But if they said, "Wanna go gym?" he would say "No." His trainers began to talk about other locations, saying "I'm on the chair" and "Let's put you on the chair!" After some time, he started to include these other locations (knee, chair, back) in this construction, even though his trainers had never modeled these combinations for him (Pepperberg, 1987c).

Starting in 1981, Alex's trainers modeled use of the word want with the $M / R$ technique with two of his favorite toys, paper and cork. His trainers would say "WANT cork," emphasizing want. At first, Alex wouldn't produce want, because he had previously obtained objects without saying it, but once his trainers made it a requirement, the word entered his vocabulary. Eventually, he combined want with several other words: "Wanna nut," "Want showah [shower]," "Want cork," "Want cracker," and "Want some water," even though his trainers had not used these expressions (Pepperberg, 1987c).

These anecdotes indicate that Alex has three categorybased rules: (1) property word + object word, (2) wanna go + location word, and (3) want/wanna + object word. Rule 1 is the most general of the three, composed as it is entirely of word categories. Rules 2 and 3 are less general, because they are anchored by specific vocabulary items; nonetheless, the fact that they include word categories makes them highly generative.

Ake and Phoenix. Herman (1987) has assessed the dolphins' knowledge of syntax by presenting them with commands that were novel either lexically or syntactically. In the lexically novel case, known words were inserted for the first time into familiar syntactic frames; in the syntactically novel case, known words were arranged into novel configurations that were natural extensions of the dolphins' languages.

Both dolphins performed well on tests of lexical novelty. Ake was wholly correct about $59 \%$ of the time (220 trials out of 372), ${ }^{6}$ whereas Phoenix was wholly correct about $67 \%$ of the time (138/207). When they made errors, they almost always did so on single words ( $78 \%$ of the time for Ake and $87 \%$ of the time for Phoenix), typically taking the transport object to the wrong destination. Both also performed well on the tests of structural novelty, of which there were three types. The first type of novelty consisted of a relational sentence with a modifier attached to either the transport or the destination word, as in PERSON LEFT FRISBEE FETCH (for Ake) and FRISBEE FETCH BOTTOM HOOP (for Phoenix). Phoenix and Ake were wholly correct on $63 \%$ (17/27) and 64\% (44/69) of these, even though neither had been trained on this particular construction before. In the second type of structural novelty, given only to Phoenix, the action term FETCH was linked with the terms OVER, UNDER, and THROUGH to form the commands FRISBEE FETCH THROUGH/OVER/UNDER HOOP (where FRISBEE and HOOP were always the transport and destination objects). The object of these commands was to carry the frisbee through, over, or under the hoop, which differed from the more standard request to take the frisbee to the hoop, made with the command FRISBEE FETCH HOOP. Phoenix performed wholly correctly on $53 \%$ of these trials $(23 \mathrm{i} / 436)$. In the third type of structural novelty, also given only to Phoenix, two nonrela- 
tional sequences were conjoined, as in PIPE TAIL-TOUCH PIPE OVER (an instruction to touch the pipe with her tail and then leap over it). Phoenix successfully performed both actions on 11 of 15 trials.

What do these responses to lexical and structural novelty tell us? According to Herman (1987), they reveal "an understanding of the learned syntactic rules sufficient for an interpretation of extensions to those rules or even exceptions to those rules" (p. 25). It is significant that both dolphins carried out entirely correct responses to more than half of the commands with new words. This suggests that their knowledge of structure is to some extent based on categories of words - objects, actions, modifiers - rather than on relations among specific items like FETCH and HOOP. They need not have experienced specific words in combination in order to execute a command successfully.

Kanzi. To analyze Kanzi's utterances for evidence of syntactic regularity, G\&SR classified them according to the system of semantic relations established by Brown (1973) for the analysis of child language. Ten major relations accounted for slightly more than $93 \%$ of Kanzi's corpus: conjoined actions, agent-action, action-object, agent-object, entity-demonstrative, goal-action, conjoined entities, conjoined locations, location-entity, and entity-attribute. (Note that these are merely labels for the relations and do not reflect Kanzi's ordering preferences.) Of the eight major relations in Brown's corpus (accounting for $70 \%$ of the utterances), seven were also found in Kanzi's production (along with one otherconjoined actions - not found in Brown's corpus). Of the seven major relations involving different types of referents (i.e., all nonconjoined relations), four showed a statistically significant preference for order: action-agent, entity-demonstrative, goal-action, and object-agent.

Do these order preferences reflect a category-based rule system? With one exception, Kanzi combined lexigrams too infrequently to permit statistical analysis. The exception was the action-object relation, which appeared late in the study and showed a preference for placing the action lexigram before the object lexigram. For all the other relations, Kanzi preferred to combine lexigrams with gestures, almost always placing the gesture after the lexigram. According to G\&SR, this pattern reflects Kanzi's invention of a "highly significant ordering rule, 'place lexigram first' "' (p. 560). This pattern was especially striking in the action-agent relation, as it inverted the agent-action order used by his caretakers. Importantly, the lexigram ordering rule was not limited to combinations of action lexigrams with demonstrative gestures; it also applied to combinations of goal lexigrams with action gestures (e.g., TOOLROOM + [go]). For G\&SR, the wide applicability of the lexigram-first rule implies great creativity on Kanzi's part. The lexigram ordering rule, they write, "involved relations between two categories $\ldots$ : a larger category of lexigrams and a smaller category of gestures" (p. 560).
This last statement deserves some scrutiny. In human language, the categories over which syntactic rules are defined are collections of words that share syntactic environments-nouns, verbs, adjectives, and so on. Kanzi's system, by contrast, appears to have just one rule, which orders elements according to the modality in which they are expressed-lexigrammatic or gestural. His invention of modality-based categories is not uninteresting, but it is utterly unlike anything found in human language. ${ }^{7} \mathrm{At}$ the very least, the lexigram ordering rule supersedes any ordering based on traditional categories such as agent and patient. ${ }^{8}$

Is Kanzi's knowledge of English syntax based on categories? His high level of performance with unusual sentences (e.g. "Put the money in the mushrooms") suggests that he understood the possible orders of words based on category-object word, action word, location word, and so on. ${ }^{9} \mathrm{Had}$ his knowledge of structure been based on the orderings of particular words, Kanzi would have balked far more often that he did, unable to interpret the novel orderings presented to him.

\section{Argument Structure?}

Alex. Alex has learned so few action words that it is difficult to say what, if anything, he knows about how events and their participants are related linguistically. Altogether, Alex knows six action words and phrases. Two are requests (want $X$, wanna go $X$ ) and four are commands (go away, come here, go X, and you tickle me; Pepperberg, 1990b). In order to test Alex's knowledge of predication, Pepperberg would need to teach him more verbs and train him to act out different commands.

Ake and Phoenix. Do the dolphins recognize that actions have two arguments (the dolphin and the object), whereas relations have three arguments (the dolphin, the transport object, and the destination object)? To answer this question, we can examine Ake's responses to syntactically anomalous relational commands containing extraneous arguments--extra destination or transport objects (Herman, Kuczaj, \& Holder, 1993; anomalies of this type were not given to Phoenix). If Ake recognizes the syntactic anomaly, she might well refuse to enact the command. As Herman et al. (1993) put it, "Recognition of an anomaly is shown by rejection, because such rejections are virtually absent for normal sequences, even when the particular combination of items has not been experienced before" (p. 186).

Ake was given 18 nonrelational anomalies with an extra object term: six with the form DDA (destination + destination + action), of which she rejected 4 (responding to the action only twice and in neither case to a named object); 6 with the form DTA (destination + transport + action), of which she rejected none (in five cases enacting the legitimate nonrelational subset TA, and in the final case creating a relation between the destination and transport objects); and 6 with the form TDA, of which she rejected only 2 (although she executed the named action 
and used a named object in just one case each). Ake was also given 19 relational anomalies with an extra transport or destination object: seven with the form DDTR (destination + destination + transport + relation), of which she rejected $1 ; 6$ with the form DTDR, of which she again rejected 1; and 6 with the form DTTR, of which she rejected none. In each of the 17 enactments, she extracted a normal relational subset from the anomaly (either DTR or TTR), restricting herself to the objects named in 12 of those enactments.

The inconsistency of Ake's responses makes it hard to evaluate her knowledge of argument number. For the nonrelational anomalies, she sometimes rejected the command outright (especially when the sequence contained no transport item) and sometimes repaired it (by deleting the extra argument). For the relational anomalies, she almost always chose repair. Do these strategies reflect recognition of anomaly? Perhaps, but it's not obvious what else Ake could have done when confronted with these commands besides reject or repair them. The crucial question is whether these strings struck Ake as ungrammatical (as, say, Julie ate her soup her dessert would strike a human listener) or whether she just found them impossible to enact and so either rendered them sensible or did nothing. Unfortunately, we cannot know how these sequences "felt" to Ake, as she cannot articulate grammaticality judgments. Her knowledge of argument number thus remains uncertain.

What do Ake and Phoenix know about the linking between thematic role and syntactic position? Consider that both animals received relational sentences in which the two objects could sensibly be switched and still result in an executable command. Out of all relational sentences in which reversals were possible, both Phoenix and Ake made just 1 reversal each (out of a possible 85 and 48, respectively; Herman et al., 1984). Their remarkable accuracy suggests that they understood the links between syntactic position and thematic role. Had they not understood these links, they would have made far more reversal errors.

Ake also received a form of semantic anomaly that tested her knowledge of linking (Herman, 1993). She was given six commands of the form TDR, ${ }^{10}$ in which the transport and destination objects were reversed (e.g., BASKET SPEAKER FETCH). " She rejected two of these commands outright. For three of the remaining four, she constructed relational responses, using $\mathrm{OBJECT}_{1}$ (a transportable object in destination position) as the destination for a randomly chosen transportable object. For the final sequence, she executed an irrelevant response. In no case did she invert the transport and destination objects, even though doing so would have corrected the anomaly-revealing once again an understanding of the links between position and thematic role.

Kanzi. According to G\&SR, Kanzi systematically encodes the relation of events to their participants. Indeed, they claim, his system shows a very human pattern, namely that of ergativity. In ergative languages, the patients of transitive acts are treated, syntactically, much like the agents of intransitive acts (usually through identical morphological markings). English has some limited ergativity, as in the case of the verb sink. We can say both The torpedo sank the ship and The ship sank; the noun ship in this case can be the direct object of sink when the verb is transitive (because sinking has an agent) and the subject of sink when the verb is intransitive (because sinking lacks an agent). G\&SR claim that Kanzi placed both intransitive agents and transitive patients after the action symbol, thus showing evidence of ergativity. From this they conclude that "a bonobo chimpanzee spontaneously created one of the two logically possible grammatical groundplans utilized by all human languages" (G\&SR, p. 573).

Ergativity in Kanzi's system would have deep implications. Several properties of his system argue strongly against this claim, however. Recall that Kanzi's productions were limited almost exclusively to two elements. Thus, any combination containing an action term could contain in addition only one of its arguments. Note, in addition, that actions were almost always labeled with lexigrams (Kanzi having only three action gestures). Because he overwhelmingly preferred to combine lexigrams with gestures, the one argument to appear with any given action term was almost always labeled with a gesture. And because of Kanzi's lexigram ordering rule, that argument always appeared after the action lexigram, regardless of its thematic role. Thus, whatever Kanzi knows about the linking in his system between thematic role and syntactic position is obscured by the lexigram ordering rule.

What does Kanzi know about the links between syntactic position and thematic role in English? To answer

Table 1

Types of "Reversed" Sentence Pairs Present to Kanzi and Percentage of Correct Responses on Each

\begin{tabular}{llllc}
\hline \multicolumn{1}{c}{ Type of Reversed Sentence } & \multicolumn{1}{c}{ Example } & \multicolumn{2}{c}{ Pairs Correct } \\
\cline { 4 - 5 } A: different word order, different verb & "Take the potato outdoors"/ & Proportion \\
B: identical word order, different verb & $\begin{array}{l}\text { "Go outdoors and get the potato" } \\
\text { "Take the rock outdoors"/ } \\
\text { C: identical verb, different word order }\end{array}$ & $\begin{array}{l}\text { "Go get the rock that"s outdoors" } \\
\text { "Put the hat on your ball" } \\
\text { "Put the hall on the hat" }\end{array}$ & 57 & $8 / 17$ \\
\hline
\end{tabular}


this question, we can inspect his performance on pairs of reversed sentences - that is, pairs of sentences with precisely the same objects and locations arranged in different positions and/or with different verbs, so as to require different responses. When he succeeds on both items of a pair, we can assume that he is not simply "guessing" but understands both the meanings of the words and the links between syntactic position and thematic role. From their data set, Savage-Rumbaugh et al. (1993) assembled (post hoc) a set of 58 such pairs, subdivided into three types: changed word order and changed verb (Type A), identical word order with different verb (Type B), and identical verb with different word order (Type C). Examples of each type are listed in Table 1.

Kanzi clearly comprehends more than just the words in these sentences: He comprehends both the words and their relations to one another, as specified by the structure. His success on Type B suggests an understanding of verb meaning, and the influence of verb meaning on the thematic roles of the noun phrases: Take the rock and get the rock mean different things for him-even though rock has the same syntactic position in both cases (direct object). Type $C$ is an especially strong case, because both sentences in a pair use precisely the same object, location, and action words. To comprehend both items of a pair correctly, Kanzi must rely exclusively on links between syntactic position and thematic role. If we assume that the probability of getting one sentence right, given a knowledge of the words, is .50 (a very conservative estimate, considering the number of possible responses), the probability of being correct on both items in a pair is .25 . Kanzi succeeded on 12 out of 21 such pairs, a level of performance well above chance (Tomasello, 1994). ${ }^{12}$

Does Kanzi know how many arguments each verb has? Unfortunately, no tests have yet been conducted, either on his production or on his comprehension, to answer that question. In the conclusion, I will suggest two tests that might prove informative.

\section{Closed-Class Items?}

Alex. Two words in Alex's vocabulary might qualify as closed-class items. The word what marks a question, both in input and in production. Alex uses what to request information about objects in his environment (e.g., asking "What color?" of novel objects), but it never appears in his responses to questions posed by his trainers. Similarly, the word want serves to mark requests: If Alex wants to play with a key, for instance, he must say "Want key"; "key" alone is not enough.

Although what and want serve to mark particular modes of interaction (question and request), they do not, as many other closed-class words do, restructure the concepts being described. Alex has not acquired articles, prepositions, tense markers, or the plural marker. Pepperberg has considered teaching Alex to pluralize but has not pursued this idea, because Alex has trouble with sibilants and would likely be unable to affix the sound $/ \mathrm{s} /$ to the ends of his object words (Pepperberg, 1987b, p. 43).
Ake and Phoenix. One of the most intriguing pieces of data from the dolphins' performance was Phoenix's moderate level of success interpreting novel relational commands with the terms OVER, UNDER, and THROUGH, as in FRISBEE FETCH UNDER HOOP. The English equivalents of these terms are prepositions and therefore belong to the set of closed-class elements. Does this mean that Phoenix has some knowledge of closed-class elements and their syntactic properties? I believe that the answer is no, as relational sentences with OVER/UNDER/THROUGH are really conjoined sentences in disguise. They were first taught as ACTION terms and are even glossed by Herman with the word Go preceding them (e.g., [go] UNDER). ${ }^{13}$ The upshot of this is that Phoenix appears to have interpreted FRISBEE FETCH UNDER HOOP as "Fetch the frisbee and go under the hoop." Her enactment indicates that these words continue to function like open-class words in human language, even when combined in this way. Although dolphins no doubt possess sophisticated knowledge of spatial relations, there is as yet no evidence that they can learn closed-class items specifying these relations.

Kanzi. Kanzi shows no evidence of possessing anything like closed-class elements in his lexigrammatic system. Of course, he was not taught any lexigrams of this type, and he could hardly have been expected to invent new Yerkish symbols. But he could have modified his gestures to indicate (for instance) number or spatial relationship (as speakers of signed languages do; cf. Klima \& Bellugi, 1979). G\&SR report, however, that "There was no evidence for morphological modification in Kanzi's gesture repertoire" (p. 555). The authors do not indicate how they made this evaluation. But if we presume its accuracy (and discount the possibility that Kanzi's morphological capacities were obscured by his relative lack of manual dexterity), we must conclude that Kanzi's production lacks this element of language.

Savage-Rumbaugh et al. have elected to focus on Kanzi's knowledge of word order in English and have not examined his knowledge of closed-class items. In no case did Kanzi have to rely exclusively on the meaning of a preposition, say, or a plural marker to correctly enact a command. Consequently, we do not know whether Kanzi understands closed-class elements in English.

\section{GENERAL DISCUSSION}

All three species we have discussed show evidence of both discrete combinatorics and category-based rules. The dolphins and Kanzi show knowledge of argument structure (although for Kanzi, only in his comprehension of English). The capacities that underlie these three properties of syntax, then, do not appear uniquely human. No species as yet shows any evidence of knowing closed-class items; whether this component of syntax will prove itself to be a preserve of Homo sapiens remains to be seen.

Two central questions now pose themselves: What more can we learn from these animals about their syn- 
tactic capacities? And why have they succeeded so well in acquiring their respective systems?

\section{Suggested Experiments}

The three research teams whose work I have considered are to be lauded for their persistence, their commitment to methodological rigor, and their experimental creativity. We know more now than we ever have about the linguistic capacities of nonhuman animals. Nonetheless, we could learn even more from these animals-especially about their knowledge of argument structure and closed-class items. Below I suggest several experiments to further explore what Alex, Ake, Phoenix, and Kanzi know about these elements of syntax. Note that I suggest further study of argument structure only for the dolphins and for Kanzi; these experiments could certainly be adapted for Alex as well, should he prove to be capable of learning more verbs.

Argument structure. An important question about Kanzi is whether he understands the relation between a verb's meaning and the number of arguments it takes. To answer this question about his knowledge of Yerkish, Savage-Rumbaugh and her colleagues could perform a socalled production probability analysis. Goldin-Meadow (1979) has shown, both for normal hearing 2-year-olds and for deaf children isolated from linguistic input and forced to invent a system of gestural communication, that the probability of naming the agent with a verb in a twoelement string decreases as the number of arguments associated with the verb increases. As the number of arguments competing with the agent for access to the one available slot goes up, the likelihood that the agent will "win" (and thus appear in the string) goes down. If Kanzi's utterances show a similar pattern, we could attribute to him an understanding that verbs vary in the number of arguments they take.

Savage-Rumbaugh and colleagues could test Kanzi's knowledge of argument number in English by confronting him with syntactic anomalies like those given to Ake. Will he refuse to enact a command with a missing argument or with one argument too many? To be sure, interpretation of such refusals is fraught with complications (because we cannot know why they happen), but it would give us more information than we currently have about Kanzi's knowledge of argument structure.

If these animals understand the links between syntactic position and thematic role, they should be able to use their knowledge of syntax to help them learn the meanings of new words. In a classic study, Brown (1957) demonstrated that children can exploit links between syntax and semantics to help them figure out what new words mean. Brown (1957) showed preschoolers a picture of hands sifting through confetti in a striped bowl. After the children had inspected the picture, he asked them to point to "the seb," "some seb," or "sebbing." In response, they pointed to the bowl, the confetti, and the hands, respectively. Children are, thus, able to infer the semantic flavor of a label from its syntactic context - that is, whether it refers to an object, a substance, or an action. Work over the last decade has added considerably to Brown's original insight: It is now clear that human learners can exploit highly subtle links between syntax and semantics to learn the meanings of nouns (e.g., Bloom, 1994), verbs (e.g., Fisher, Hall, Rakowitz, \& Gleitman, 1994), and prepositions (e.g., Landau, Smith, \& Jones, 1988).

We could test for such knowledge in language-trained animals by repeating Brown's experiment-that is, by introducing a novel label (word/sign) in a complete sentence and asking what the animal has learned about the meaning of that word. Can Ake learn from a novel word's syntactic position that it refers to a transport object? To find out, Herman and his colleagues could give the command PIPE [NOVEL. SIGN] FETCH ("bring the [novel transport object] to the pipe") in the presence of a pipe (a familiar destination object), a vertical pole affixed to the pool floor (a novel destination object), a ball (a familiar transport object), and a life preserver (a novel transport object). If Ake can infer a word's semantic class from its syntactic position, she should learn that the novel sign refers to the life preserver.

Similar experiments could be done with Kanzi, both in Yerkish and in English. Because Kanzi's caretakers produce Yerkish with English word order, we might expect him to understand how syntax and semantics are related in their dialect. His caretakers could produce a lexigrammatic utterance such as SUSAN [NOVEL LEXIGRAM] SALLY while Susan turns Sally. Would Kanzi learn that the new lexigram meant "turn"? Precisely the same thing could be done in English, using a novel verb like gorp. Studies such as this would, of course, be quite difficult to do with Alex, inasmuch as he knows so few verbs - a further incentive, in my view, to teach him more verbs.

Closed-class items. To my mind, the most pressing unresolved issue is whether these animals can acquire closed-class items. It should, in principle, be a straightforward matter to find out. Pepperberg could teach Alex the prepositions in and on and then train him to answer questions about location - for example, "Where peg?" In this case he would have to answer either "in box" or "on box." To see whether the dolphins can learn spatial prepositions, Herman and his colleagues could teach them the two-element relations PUT IN and PUT ON (where the sign or signal for PUT is the same in both cases). If they could learn to locate an object differently as a function of the preposition, they would be showing knowledge of a closed-class item. If Kanzi knows the difference between in and on in English, he should respond to the sentence "Put the tomato in the box" by doing just that, whereas he should respond to "Put the tomato on the box" by closing the box and placing the tomato on the top surface. One could also test Kanzi's knowledge of the plural by contrasting his response to "Take the ball to [person]" with "Take the balls to [person]"; in the first case, he should transport only one ball, whereas in the second, he 
should transport more than one. Adding closed-class items to Yerkish might prove difficult, but it seems to me to be worth trying.

\section{Origins of Syntactic Abilities}

Whether any of these animals can acquire closed-class items or pass any of the other tests suggested above, the fact remains that they are not ordinary learners. Alex and the dolphins had to be prodded and cajoled into linguistic competence, and, although Kanzi acquired both Yerkish and English without intensive training, his competence in both systems never exceeds that of the average 2-year-old. Their status as special learners aside, however, these animals have nonetheless attained impressive levels of linguistic ability, levels thought by many to be impossible. What has enabled their achievements? Do their capacities under human tutelage reflect the capacities of their counterparts in the wild, or has language training altered them in some fundamental way?

This question-What is native and what added by language?-has long challenged animal language researchers. Premack, in his seminal work with the chimpanzee Sarah, argued that language training enhances at least some aspects of cognition (e.g., Premack, 1983, 1984). Pepperberg, by contrast, has written that "training is unlikely to allow an animal to acquire a concept it would otherwise be incapable of learning" (1993, p. 224). Savage-Rumbaugh et al. (1993) have taken an intermediate position: Although acknowledging the importance of Kanzi's unusual environment, they attribute his linguistic capacities to a neural plasticity shared by all higher primates.

We propose that human competence for language-and also Kanzi's - is a reflection of genetically defined possible modes of development that are responsive to environmental complexity. It is both the plasticity and the inherent similarity between ape and human brains that permits them to lay down the structures of complex systems, such as language, during infant development. (p. 104)

Could the notion of neural plasticity explain the achievements of Alex and the dolphins as well? Perhaps. But this possibility raises a further question: What exactly are these animals doing in the wild with such plastic brains? These questions are enormously difficult to answer, because we know so little about their cognitions uncontaminated by human influence.

Despite our ignorance, we can make some guesses about which native capacities might enable success in language training. The capacity shown by all for discrete combinatorics may have its roots in perception and action: In order to move about and behave adaptively, organisms must inventory the contents of their environment. It simply will not do for the world to be an undifferentiated mass of stuff. The world must instead be carved into trees, other animals, water, rocks, and so on-discrete entities, each with unique, highly relevant properties. Category-based rules may also have their roots in perception and action: Decisions about how to behave must be made relative to categories of thingsfood, predators, mates, allies, enemies, children, habitats, and so on. The decision rules (or algorithms) which apply in one domain will not work in another (Tooby \& Cosmides, 1992), thus making knowledge of categories essential. Finally, the capacity shown by the dolphins and by Kanzi for argument structure may have its origins in social intelligence: Any highly social animal must keep track of who has done what to whom-events and their agents and patients - so that it can make alliances, jockey for position in the social hierarchy, mate, and raise its young (cf. Cheney \& Seyfarth, 1990).

The research I have considered in this paper suggests that several of the core properties of human syntax lie within the grasp of other animals. Evolutionarily, this makes excellent sense: Modern human language could not have been created out of nothing, in a single, massive mutation. Rather, it must have evolved in stages, each building on preexisting capacities. It is reasonable to suppose that the capacities displayed by Alex, Ake, Phoenix, and Kanzi were among the building blocks for language and that a random mutation (or sequence of mutations) led to their being integrated and put, collectively, to a new (and massively adaptive) purpose (Bickerton, 1990, 1995). In this light, questions about the species specificity of language assume a new character. Rather than ask, "Is language species specific?" we must ask instead, "Which components of language are species specific?" Although significant progress has been made in answering this question, further work clearly needs to be done, particularly on the capacity to acquire closed-class items.

\section{REFERENCES}

BAKER, M. C. (1992). Thematic conditions on syntactic structures: Evidence from locative applicatives. In I. M. Roca (Ed.), Thematic structure and its role in grammar (pp. 23-46). Berlin: Foris Publications.

BerRidGe, K., FENTRESS, J. C., \& PARR, H. (1987). Natural syntax rules control action sequences of rats. Behavioral \& Brain Sciences, 23, 59-68.

BICKERTON, D. (1990). Language and species. Chicago: University of Chicago Press.

BICKERTON, D. (1995). Language and human behavior. Seattle: University of Washington Press.

BLoOM, P. (1994). Possible names: The role of syntax-semantics mappings in the acquistion of nominals. Lingua, 92, 297-329.

BROWN, R. (1957). Linguistic determinism and the parts of speech. Journal of Abnormal \& Social Psychology, 55, 1-5.

Brown, R. (1973). First language: The early stages. Cambridge, MA: Harvard University Press.

CAPLAN, D. (1992). Language: Structure, processing, and disorders. Cambridge, MA: MIT Press.

Cheney, D. L., \& Seyfarth, R. M. (1990). How monkeys see the world. Chicago: University of Chicago Press.

CHOMSKy, N. (1965). Aspects of the theory of syntax. Cambridge, MA: MIT Press.

DEMERS, R. A. (1988). Linguistics and animal communication. In F. J. Newmeyer (Ed.), Linguistics: The Cambridge survey: Vol. III. Language: Psychological and biological aspects (pp. 314-335). New York: Cambridge University Press.

DowTY, D. (1991). Thematic proto-roles and argument selection. Language, 67, 547-619. 
Fisher, C., Hall, D. G., Rakowitz, S., \& Gleitman, L. (1994). When it is better to receive than to give: Syntactic and conceptual constraints on vocabulary growth. Lingua, 92, 333-375.

Gleitman, L. R., Gleitman, H., Landau, B., \& Wanner, E. (1988). Where learning begins: Initial representations for language learning. In F. J. Newmeyer (Ed.), Linguistics: The Cambridge survey: Vol. III. Language: Psychological and biological aspects (pp. 150-193). New York: Cambridge University Press.

GoldBerg, A. E. (1995). Constructions: A construction approach to argument structure. Chicago: University of Chicago Press.

Goldin-Meadow, S. (1979). Structure in a manual communication system developed without a conventional language model: Language without a helping hand. In H. Whitaker \& H. A. Whitaker (Eds.), Studies in neurolinguistics (Vol. 4, pp. 125-209). New York: Academic Press.

Greenfield, P. M., \& Savage-Rumbaugh, E. S. (1990). Grammatical combinations in Pan paniscus: Processes of learning and invention in the evolution and development of language. In S. T. Parker \& K. R. Gibson (Eds.), "Language" and intelligence in monkeys and apes: Comparative developmental perspectives (pp. 540-578). New York: Cambridge University Press.

Grimshaw, J. (1990). Argument structure. Cambridge, MA: MIT Press.

HAEGEMAN, L. (1991). Introduction to government and binding theory. Cambridge, MA: Blackwell.

Herman, L. M. (1987). Receptive competencies of language-trained animals. In J. S. Rosenblatt, C. Beer, M.-C. Busnel, \& P. J. B. Slater (Eds.), Advances in the study of behavior (Vol. 17, pp. 1-60). Orlando, FL: Academic Press.

Herman, L. M. (1989). In which procrustean bed does the sea lion sleep tonight? Psychological Record, 39, 19-50.

Herman, L. M., KuczaJ, S. A., II, \& Holder, M. D. (1993). Responses to anomalous gestural sequences by a language-trained dolphin: Evidence for processing of semantic relations and syntactic information. Journal of Experimental Psychology: General, 122, 184-194.

Herman, L. M., Richards, D. G., \& Wolz, J. P. (1984). Comprehension of sentences by bottlenosed dolphins. Cognition, 16, 129-219.

Hockett, C. F., \& Altmann, S. A. (1968). A note on design features. In T. A. Sebeok (Ed.), Animal communication (pp. 61-72). Bloomington: Indiana University Press.

HOFFMEISTER, R., \& MOORES, D. F. (1987). Code switching in deaf adults. American Annals of the Deaf, 132, 31-34.

JACKENDOFF, R. (1983). Semantics and cognition. Cambridge, MA: MIT Press.

JACKENDOFF, R. (1987). The status of thematic relations in linguistic theory. Linguistic Inquiry, 18, 369-411.

Klima, E. S., \& Bellugi, U. (1979). The signs of language. Cambridge, MA: Harvard University Press.

Landau, B., Smith, L. B., \& Jones, S. S. (1988). The importance of shape in early lexical learning. Cognitive Development, 3, 299-321.

LEVIN, B. (1993). English verb classes and alternations: A preliminary investigation. Chicago: University of Chicago Press.

MarLer, P. (1984). Song learning: Innate species differences in the learning process. In P. Marler \& H. S. Terrace (Eds.), The biology of learning (pp. 289-309). Berlin: Springer-Verlag.

MCNEILL, D. (1970). The acquisition of language: The study of developmental psycholinguistics. New York: Harper \& Row.

MorRow, D. G. (1986). Grammatical morphemes and conceptual structure in discourse processing. Cognitive Science, 10, 423-455.

Myers-SCotTon, C. (1993). Duelling languages: Grammatical structure in codeswitching. Oxford: Oxford University Press, Clarendon Press.

Partee, B. (1995). Lexical semantics and compositionality. In D. N Osherson (Series Ed.) \& L. R. Gleitman \& M. Liberman (Eds.), An invitation to cognitive science: Vol. 1. Language (2nd ed., pp. 311360). Cambridge, MA: MIT Press.

Pepperberg, I. M. (1981). Functional vocalizations by an African Grey parrot (Psittacus erithacus). Zeitschrift für Tierpsychologie, $\mathbf{5 5}$, 139-160.

Pepperberg, I. M. (1983). Cognition in the African Grey parrot: Preliminary evidence for auditory/vocal comprehension of the class concept. Animal Learning \& Behavior, 11, 179-185.

Pepperberg, I. M. (1987a). Acquisition of the same/different concept by an African Grey parrot (Psittacus erithacus): Learning with respect to categories of color, shape, and material. Animal Learning \& Behavior, 15, 423-432.

PepperberG, I. M. (1987b). Evidence for conceptual quantitative abilities in the African Grey parrot: Labeling of cardinal sets. Ethology, 75, 37-61.

PePperberg, I. M. (1987c). Interspecies communication: A tool for assessing conceptual abilities in the African Grey parrot. In G. Greenberg \& E. Tobach (Eds.), Cognition, language, and consciousness: Integrative levels (pp. 31-56). Hillsdale, NJ: Erlbaum.

PePPERBERG, I. M. (1988). Comprehension of "absence" by an African Grey parrot: Learning with respect to questions of same/different. Journal of the Experimental Analysis of Behavior, 50, 553-564

PePperberg, I. M. (1990a). Cognition in an African Gray parrot (Psittacus erithacus): Further evidence for comprehension of categories and labels. Journal of Comparative Psychology, 104, 41-52.

Pepperberg, I. M. (1990b). Referential mapping: A technique for attaching functional significance to the innovative utterances of an African Grey parrot (Psittacus erithacus). Applied Psycholinguistics, 11, 23-44.

Pepperberg, I. M. (1992). Proficient performance of conjunctive, recursive task by an African Grey parrot (Psittacus erithacus). Journal of Comparative Psychology, 106, 295-305.

Pepperberg, I. M. (1993). Cognition and communication in an African Grey parrot (Psittacus erithacus): Studies on a nonhuman, nonprimate, nonmammalian subject. In H. L. Roitblat, L. M. Herman, \& P. E. Nachtigall (Eds.), Language and communication: Comparative perspectives (pp. 221-248). Hillsdale, $\mathrm{NJ}$ : Erlbaum.

PINKer, S. (1989). Learnability and cognition. Cambridge, MA: MIT Press.

PINKER, S. (1994). The language instinct: How the mind creates language. New York: Morrow.

Premack, D. (1983). The codes of man and beasts. Behavioral \& Brain Sciences, 6, 125-167.

Premack, D. (1984). Upgrading a mind. In T. G. Bever, J. M. Carroll, \& L. A. Miller (Eds.), Talking minds: Approaches to the study of language in cognitive science (pp. 181-206). Cambridge, MA: MIT Press.

Ristau, C. A., \& Robbins, D. (1982), Language in the great apes: A critical review. In J. S. Rosenblatt, C. Beer, M.-C. Busnel, \& P. J. B. Slater (Eds.), Advances in the study of behavior (Vol. 12, pp. 141255). Orlando, FL: Academic Press.

Savage-Rumbaugh, E. S., Murphy, J., Sevcik, R. A., Brakke, K. E., Williams, S. L., \& Rumbaugh, D. M. (1993). Language comprehension in ape and child. Monographs of the Society for Research in Child Development, 58 (Nos. 3-4).

Savage-Rumbaugh, E. S., Rumbaugh, D. M., \& Boysen, S. (1978). Symbolic communication between two chimpanzees (Pan troglodytes). Science, 201, 641-644.

Savage-Rumbaugh, E. S., Rumbaugh, D. M., Smith, S. T., \& Lawson, J. (1980). Reference: The linguistic essential. Science, 210, 922-925.

Schusterman, R. J., \& Gisiner, R. C. (1988). Artificial language comprehension in dolphins and sea lions: The essential cognitive skills. Psychological Record, 38, 311-348.

Schusterman, R. J., \& Gisiner, R. C. (1989). Please parse the sentence: Animal cognition in the procrustean bed of linguistics. Psychological Record, 39, 3-18.

Schusterman, R. J., \& Krieger, K. (1984). California sea lions are capable of semantic comprehension. Psychological Record, 34, 3-23.

SeidenberG, M. S., \& Pettrto, L. A. (1979). Signing behavior in apes: A critical review. Cognition, 7, 177-215.

SRidhar, S. N., \& Sridhar, K. K. (1980). The syntax and psycholinguistics of bilingual code mixing. Canadian Journal of Psychology, 34, 407-416.

Stowell, T. (1992). The role of the lexicon in syntactic theory. In T. Stowell \& E. Wehrli (Eds.), Syntax and semantics (Vol. 26, pp. 920). San Diego, CA: Academic Press.

TALMY, L. (1985). Lexicalization patterns: Semantic structure in lexical forms. In T. Shopen (Ed.), Language typology and syntactic description (pp. 57-149). Boston: Cambridge University Press

TALMY, L. (1988). The relation of grammar to cognition. In B. Rudzka- 
Ostyn (Ed.), Topics in cognitive linguistics (pp. 165-205). Philadelphia: Benjamins.

Terrace, H. S., Pettito, L. A., Sanders, R. J., \& Bever, T. G. (1979). Can an ape create a sentence? Science, 206, 891-902.

TOMASELLO, M. (1994). Can an ape understand a sentence? A review of Language comprehension in ape and child by E. S. Savage-Rumbaugh et al. Language \& Communication, 14, 377-390.

TOOBY, J., \& Cosmides, L. (1992). The psychological foundations of culture. In J. H. Barkow, L. Cosmides, \& J. Tooby (Eds.), The adapted mind: Evolutionary psychology and the generation of culture (pp. 19136). Oxford: Oxford University Press.

VANDELoISE, C. (1994). Methodology and analyses of the preposition in. Cognitive Linguistics, 5, 157-184.

vaN HouT, A. (1996). Event semantics of verb frame alternations. Tilberg, The Netherlands: Tilberg University.

Van Petten, C., \& Kutas, M. (1991). Influences of semantic and syntactic context on open- and closed-class words. Memory \& Cognition, 19, 95-112.

\section{NOTES}

1. I here omit any discussion of the ape language projects of the 1970 s, as the shortcomings of those projects have been extensively documented elsewhere. See, for instance, Ristau and Robbins (1982), Seidenberg and Pettito (1979), and Terrace, Pettito, Sanders, and Bever (1979).

2. Ronald Schusterman and his colleagues have also trained a marine mammal, the California sea lion Zalophus californianus, in an artificial gesture system (Schusterman \& Gisiner, 1988; Schusterman \& Krieger, 1984). I have chosen not to include the sea lions in my analysis, in part because the dolphins were the first language-trained cetaceans and in part because Schusterman has denied that the sea lions show linguistic competence. (He has also denied that the dolphins show such competence-see, especially, the dialogue between Schusterman \& Gisiner, 1989, and Herman, 1989.)

3. In many languages, of course, thematic roles are indicated by morphological markings (inflections), rather than by syntactic position. Partly because these animals have all learned position-based systems, and partly because it facilitates exposition, I will restrict myself to speaking just of syntactic position.

4. I have simplified the notion of argument structure in at least two key ways. First, I have ignored the fact that a verb can take arguments that are not physical entities like John and book. Verbs involving mental activity, for instance, take propositional arguments, as in Marc knows that Gordon will come tomorrow, where the verb know takes one argument that is an entity (Marc) and another that is a proposition (that Gordon will come tomorrow). Second, I have neglected altogether the issue of variability in surface form. Many verbs permit their arguments to be realized in more than one way. The verb give, for example, allows its recipient to surface either as a noun phrase immediately following it ( Lisa gave CHRIS the book) or as a noun phrase embedded in a prepositional phrase following the direct object (Lisa gave the book TO CHRIS). The position taken by the argument depends on subtle facts about its role in the event (see, for instance, Pinker, 1989).

5. Again, I have simplified somewhat. There are at least four cases in which a verb does not appear with all of its arguments: (1) in socalled pro-drop languages, where subjects that otherwise would be pronouns can be omitted (e.g., in Spanish one can say simply Llegó [He came], with no subject); (2) in object-drop, where a verb's object may be deleted, provided it can be recovered from context (e.g., in Susan ate, we assume that she ate some food, and in Marcus shaved, we assume that he shaved himself); (3) in elision, where arguments are deleted when they can be recovered by reference to prior material (e.g., in Jon bought a new sweater and Gregory did too we can infer what Gregory did from what Jon did); and (4) in syntactic transformations (e.g., the active sentence The boss promoted Andrea can be changed into the passive Andrea was promoted, where the agent goes unspecified). Although these exceptions are not infrequent, they are highly lawful and do not disturb the basic generalization.

6. Note that because the dolphins can err in so many ways-through reversal of transport and destination objects, incorrect object selection, inappropriate action, and so on-they are performing well above chance even when they succeed completely only half the time (see Herman et al., 1984, for details).

7. There is one possible human analog to Kanzi's modality-based ordering rule: code-switching (movement between languages within a single sentence) among speakers fluent in both a signed and a spoken language (Hoffmeister \& Moores, 1987). In this case, however, speakers are shifting between two different rule systems, each of which must be respected (cf. Myers-Scotton, 1993; Sridhar \& Sridhar, 1980). Kanzi, by contrast, has only one rule system, which makes reference to two different modalities.

8. G\&SR admit this possibility, but only as a parenthetical comment in a footnote. In the note attached to Table 20.2, G\&SR note that Kanzi's action-object lexigram-gesture combinations had the same ordering as his action-object lexigram-lexigram combinations (the one relation for which Kanzi combined lexigrams often enough to permit analysis). Initially they write, "We could consider this phenomenon of using a demonstrative gesture rather than the object lexigram used earlier as an analogue of pronominalization development." Immediately thereafter, they qualify this comment by remarking (in parentheses), "Note that the lexigram-gesture ordering rule presented in Table 20.3 may have overdetermined the symbol ordering pattern of these examples" (p. 559).

9. Whether Kanzi can be said to have categories like noun and verb cannot be determined from the testing that Savage-Rumbaugh et al. have conducted. See Tomasello (1994) for an argument that Kanzi does not possess the category verb.

10. Herman et al. (1993) use the terms stationary instead of destination and transportable instead of transport. I have modified their notation slightly to make the thematic roles more transparent.

11. Herman classifies this anomaly as semantic, but it could also be classified as syntactic. In Ake's language, the first object word is always the destination, the second object word always the transport item. Because syntactic position and thematic roles are identical in the dolphins' languages (as they are not in human language), a command that places an immovable object in second position violates the syntax.

12. In a review of Savage-Rumbaugh et al.'s (1993) monograph, Tomasello (1994) observes that some pairs do not constitute perfect reversals. For instance, Savage-Rumbaugh et al. treat put and pour as equivalent, as in "Put the rock in the water," and "Pour the water on the rock." Prepositions also differ, as between "Put some water on the carrot" and "Put the carrot in the water." Counting only perfect reversals, Kanzi gets both items in a pair right on only 5 of 12 trials-not different from chance.

13. Note that human languages often have verbs of this type, which encode both the fact of motion and the direction of motion-for example, exit in English, which can be paraphrased as "go out" (see Talmy, 1985, for other examples, both in English and in other languages). The question is whether the dolphins can learn a sign that encodes only direction of motion and that then combines with a sign labeling only the fact of motion.

(Manuscript received September 10, 1997; revision accepted for publication July 16, 1998.) 